\title{
Well-being and Philosophy of Science
}

\begin{abstract}
This article is a mutual introduction of the science of well-being to philosophy of science and an explanation of how the two disciplines can benefit each other. In the process I argue that the science of well-being is not helpfully viewed as a social or a natural, but rather as a mixed, science. Hence its methodology will have to attend to its specific features. I discuss two of its methodological problems: justifying the role of values, and validating measures. I suggest that tackling them calls for developing mid-level rather than high theories of well-being.
\end{abstract}

\section{Introduction 1}

Why should philosophers of science be interested in well-being? Not only because they are human beings like others, but also because philosophy of science and the science of well-being stand to benefit from each other. In the past few decades the scientific study of well-being has developed from a quirky newcomer to a well-established field at the intersection of the social, medical, cognitive and policy sciences. Yet as far as philosophy of science goes, it is uncharted territory. Hence the goal of this paper is to supplement the existing reviews of the well-being literature written for ethicists and moral psychologists (e.g. Tiberius 2006) with one focused specially on two issues:

1. What sort of science is the science of well-being?

2. How could it be improved?

Answering the first question will show how a focus on the science of well-being can genuinely inform philosophy of science. I argue that it does so by challenging the outdated divisions between naturalism and interpretivism which long defined philosophy of social science. A careful look at the science of well-being shows us that it is neither a social nor a natural science, according to those old divisions. It is instead a mixed science, and since there is no reason to think that this field is unique, it is time to abandon the very project of studying general features of social science. This is the argument of Part I.

Part II answers the second question in the form of a partial agenda. I highlight two urgent and unresolved problems raised by this science that fall distinctly in the domain of philosophy of science. They are the appropriate role of moral and prudential judgments in the definition of scientific objects, and the logic of measure validation. I close with a discussion of a way forward. If the science of well-being embraces its value-ladenness and philosophers progress from refining high to formulating mid-level theories, the project might just have a chance.

\section{What sort of science is it?}


Scientific research into well-being is now a mature field known variously as happiness studies, hedonic psychology, prudential psychology, studies of subjective well-being and life satisfaction. I shall use 'the science of well-being' to refer to them all. It is mature in the sociological sense: there are professional societies, specialized journals, a wealth of publications in prime venues, policymakers' attention and other standard accouterments of a discipline. But it is also mature in the intellectual sense in that there are many sophisticated measures of well-being, causal models, and a wealth of knowledge about how to test and apply them. Thomas Kuhn's notion of 'normal science' naturally suggests itself. For Kuhn normal science started when fundamental philosophical disagreements ended and paradigm-based puzzle solving began (Kuhn 1962). Some features of the new status quo in the science of well-being make it look positively 'normal'.

First of all, the controversy about whether or not well-being can be measured at all has died down, at least in the relevant circles. At this point, the bet is that it can be and the debate has moved on to the virtues and vices of specific measures (Kahneman and Krueger 2006 among others). The second sign of normalcy is the development of more or less general causal models of well-being incorporating various determinants and risk factors at biological, psychological and social levels (Diener 2012). Well-being is no longer thought to be an idiosyncratic personal phenomenon that does not admit of population-level analysis. Connected to this, there is a growing widely accepted list of causal claims about well-being, some of which I will be mentioning in the forthcoming sections.

It may look like a normal science, but is it a social or a natural science? On the face of it, the science of well-being is a social science, pursued mostly by sociologists, economists, psychologists and clinical scientists. But, as I will argue, not much follows from this fact, as this very category of a social as opposed to natural science appears to be methodologically inert. My argument will proceed as follows:

1. Traditional divisions in philosophy of social science are supposed to mark different ideals for social and natural sciences.

2. The science of well-being shares ideals with both.

3. Therefore the science of well-being is a mixed science in this sense.

As well as offering an answer to the title question of this section, I take this argument to raise doubts about the very idea of a philosophy of social science (or of natural science, for that matter), to the extent that it purports to study general features of all and only social sciences. There is no reason to think the science of well-being to be unique in its mixedness, so to speak. So we should be very skeptical of blanket characterizations of social and natural sciences as in Premise 1.

What are these blanket characterizations? Traditionally philosophy of social science dealt with the methodological and metaphysical problems raised by social sciences specifically - whether there are laws of social science, methodological individualism, interpretation of social actions, etc. For the most part writers in this field operated with the categories of natural versus social 
science, some advocating a kind of exceptionalism of the social sciences, while others emphasized its continuity with the natural sciences. The opponents, while disagreeing, shared the presumption that these categories make sense. ${ }^{2}$

One core distinction in the old philosophy of social science is between naturalism and interpretivism. Standardly, this distinction is drawn as a debate between those who think that social science should model itself on natural science (naturalists) and those who think it has a distinct method of interpretation (interpretivists). Recently, it has been noted that natural sciences are too diverse to have a monolithic method. Indeed the many observations of the disunity of science that have grown through the 1980s and 1990s should already doom this way of carving up naturalism from interpretivism. So others argue that the real debate is about whether or not generalizable causal knowledge can be attained and used for the betterment of human condition (Steel 2010). Interpretivism espouses skepticism on this point: the best we can do is to represent human condition in all its varieties and complexities.

Of course, whether or not the science of well-being sides with naturalism or interpretivism depends entirely on how the options are carved out. It is possible to make naturalism so broad that only utter skeptics would end up as interpretivists. But importantly, such a classification seems entirely beside the point. ${ }^{3}$ Moving on to premise 2, I will discuss five core features of the science of well-being that give it features of both naturalist and interpretivist projects:

I.1. Value-ladenness. A central tenet of naturalism from as early as John Stuart Mill is value freedom: a social science is to study empirical facts and relations between them, leaving recommendations to policy makers. ${ }^{4}$ In this section I argue that the science of well-being self-consciously repudiates this ideal, does so for a good reason and is anti-naturalist in this sense. In section II.1 I will explain the special task this feature creates for philosophers of science.

There are, of course, several senses of value-ladenness. Firstly, well-being is an important thing for a society to study, so values may come in legitimately in the choice to pursue this research and in the way we organize it (as Max Weber and more recently Philip Kitcher taught). Secondly, once some empirical facts are known about the causes of well-being, it is important to be right about these facts, especially when it comes to recommending policies that might affect wellbeing. Values may then inform the judgment as to how important it is to be right and how risky it is to be wrong. ${ }^{5}$ So far, so uncontroversial. More distinct to this field, there is a third sense of value ladenness at play here: any definition of wellbeing is fundamentally normative, that is values enter into the way scientists deem certain states or properties to be constitutive of well-being and certain measures to be good indicators of well-being. Ernest Nagel, reflecting a traditional view that science is descriptive, counseled against the admission of this latter type of value-ladenness (Nagel 1961). For "thick" concepts such as efficiency, health and well-being, ${ }^{6}$ he recommended that we separate the "appraising" element from the "characterizing" one and keep our science focused only on the latter not the former (490-491). 
Although a Nagelian value-freedom still finds adherents, by and large the science of well-being does not follow his advice. Well-being researchers readily engage in normative discussions, i.e. in appraising. One example is the current debate about how to conceptualize and measure the well-being of a nation. Government agencies in UK, France, USA and elsewhere, are busy exploring the meaning and measurement of 'national well-being' (Stiglitz et al 2009). Academics have no shortage of opinions on the matter. Daniel Kahneman and Richard Layard, along with other eminent scholars, are pushing for a hedonic measure of national wellbeing - a nation is doing well to the extent that its populace has on average a favorable balance of positive over negative emotions (Kahneman et al 2004a, Layard 2005). Development economists focus rather on objective quality of life (Nussbaum and Sen 1993, Dasgupta 2001). Yet others work with a life satisfaction notion of well-being, which purports to best respect the judgment of the individual (Diener et al 2008). The debate about the proper measure of national well-being is in part a normative debate about whether well-being is just an affective state, or a subjective judgment, or an actual state of one's life.

A traditionalist objects that these normative discussions should be kept out of the science of well-being. They are part of ethics, while the science should study only what people call 'well-being', much like anthropologists might study what people call 'morality'. Such a proposal is too restrictive in my view. First, the science of well-being does not even get off the ground without value-based decisions on how and what to measure as we shall see in Part II. There are many things people might call well-being, too many to study them all, and we need values to pick among them. Second, value-freedom requires an artificial separation of pure from applied science, as it forces, say, a developmental psychologist to study only what people call child well-being but not what is actually good for children. But her applied knowledge of child development is far richer than just recording people's opinions on it. Finally, value-ladenness does not imply science can tell us how to live, if that is the worry of the traditionalist. It only does so in conjunction with normative theories, which is how it should be.

In section II.1 we will see that the precise form of the thesis is still controversial for a good reason. But at the very least, judging by the state of the science of wellbeing, the burden of proof is now on the advocate of value-freedom.

I.2. Search for causal generalizations. At the same time, well-being research is committed to the idea that the social world has causal laws or at least generalizations that could play the role of laws. In pursuing this commitment the science of well-being rejects two pillars of interpretivism: that the social world is too complex (or too open, or too free, etc.) for any meaningful generalizations, and that explanations of human actions should be couched primarily in terms of reasons not causes. The generalizations in question usually relate well-being to a socio-economic or psychological variable such as unemployment or a personality trait, or an activity, such as volunteering or commuting. 
Of course, it is one thing to be committed to this goal and another to actually find such generalizations. Does the science of well-being have any successes to show?

One area of study that has gained much attention over the years is the stability, or lack thereof, of well-being. Which changes in our environment most affect our well-being and which ones don't? Two purported effects have occupied wellbeing researchers and captured the public imagination. The first is the alleged adaptation, i.e. the ability to regain previous levels of well-being (judged by life satisfaction or happiness reports), to what seem huge changes in circumstances, such as winning the lottery, or losing mobility. The second is the fickleness of judgments of well-being: apparently finding a coin, or seeing a person in a wheelchair, or being reminded of the weather, could drastically change one's own evaluation of well-being. To explain these effects scientists postulated the set point theory - genes and early environment give us a range of happiness to which we invariably return after perturbations.

A good example of progress in testing generalizations is the recent updating, or even debunking, of these early claims. It turns out that adaptation has a fairly restricted domain and a variable pattern across people. Divorce, serious disability and unemployment are very hard to get over, while adaptation to the death of a spouse is long but doable (Lucas 2007). And judgments of life satisfaction are far more robust than claimed, so much so that the weather/coin/wheelchair effects that so excited scholars and public just a few years ago, cannot be replicated (Lucas 2013).

What about causality? Although notoriously difficult to infer from observational data, standard techniques such as randomized controlled trials and instrumental variable approaches are entering well-being research too. One recent randomized controlled trial examined the effect of job training and supplemented income on a group of poor single mothers in the UK. The findings are clear and unexpected: their subjective well-being has been lowered by greater professional expectations and greater earning power (Dorsett and Oswald 2014).

I.3. Focus on lived experience. The search for causal generalizations does not exclude genuine concern with what well-being (or ill-being) feels like and how it is understood in a social context. The classic interpretivist goal of "thick descriptions" which help us understand the meaning of actions and the content of experiences is very much present in parts of the science of well-being.

Most prominently, researchers are perfecting their tools for detecting and recording the experience of subjects in all its richness and complexity. Here the various applications of Experience Sampling Methods have become standard. Going through their day, subjects get prompted by a beeper to rate themselves on a variety of positive and negative emotions, their quality, intensity etc. Out of these ratings there emerges a picture of how a person felt as time went on and their circumstances and activities changed. Recently, using this method scholars have studied the daily experience of Texas women who famously found taking care of children to be not so pleasant (Kahneman et al 2004b). 
In addition to these newer methods, the old and trusted qualitative tools of anthropology and sociology are alive and well. These include ethnographies, open questionnaires and structured interviews. Recent examples of explicitly ethnographic research on well-being include studies of refugees (Kopinak 1999), families on welfare (Chase-Landsdale et al 2003), intensive care nurses (Einarsdóttir 2012) and many more. With the rise of cross-cultural studies of well-being, these methods become all the more prominent and important (Diener and Suh 2000, Camfield et al 2009).

Notably, even in projects far removed from the qualitative approaches - for example, inference of preferences from choices by economists - the latest methods have abandoned the skepticism about tapping human experience that characterizes the classic economic approach. There is widespread recognition that only some preferences and only some choices can reveal what really matters to people and that to detect those requires a host of psychological and cultural knowledge, and perhaps even talking to people (Benjamin et al 2014).

I.4. Measurement. As already mentioned, the normal science of well-being takes well-being to be measurable. This applies both to objective indicators (such as health, income etc) and to subjective ones (happiness, life satisfaction etc). Exactly how this measurement is done remains up for grabs in such a young field as yet unburdened with rigid common standards. Still, studying the absolute and relative levels of well-being and their reactions to various changes is a quantitative project at heart.

Erik Angner shows that two traditions currently coexist - axiomatic and psychometric - corresponding respectively to economic and psychological approaches to well-being (Angner 2009). In economics the key to the measurement of well-being is a formally defined representation relation between preferences and behavior, while in psychology and medicine the key is a valid questionnaire. Purely economic measures of well-being, the new consensus has it, are based on controversial assumptions about human rationality and fail to capture the subjective experience of our lives (Loewenstein 2009). Challenging the hegemony of measures such as GNP has been essential to the very identity of the science of well-being. But that does not mean that the psychometric tradition wins, as I argue in section II.2. For now it is sufficient to note this traditionally naturalist aspiration.

I.5. Policy hopes. The final feature of the science of well-being is its policy aspirations and, to some extent, its social activism. This field is often recruited to tell us what is wrong with the way middle class Westerners live and with what they value; from isolation, to consumerism, to the medicalization of grief and sadness. Its founders have positioned this field explicitly as an exercise in policy evaluation and recommendation (Diener et al 2008, Kahneman et al 2004 to name a few). The science of well-being, in large part, is supposed to show which policies, therapies, interventions and community arrangements relieve suffering and improve the well-being of all concerned. Some practitioners have been successful at putting themselves in the policy arena at high levels in Canada, UK, 
France, USA and increasingly elsewhere. The movement for Evidence-Based Policy has been a convenient bandwagon to jump on, as evidence about wellbeing is increasingly sought out and advertised. The proliferation of Buddhismbased approaches such as mindfulness-based stress reduction is a typical example of the science's therapeutic aspirations. ${ }^{7}$

I have examined five features of the science of well-being. The last feature, policy hope, has a complicated history with naturalism and interpretivism. But with the remaining four, we have a draw: two points for naturalism (search for causal generalizations and measurement) and two points for interpretivism (valueladenness and focus on lived experience). This is the evidence for my claim that the science of well-being is mixed. It has goals and methods typical of several scientific disciplines. We could note further features of mixedness. Mathematical modeling and elaboration of abstract theory, so important to economics, physics and parts of biology, have not arrived to well-being. Empirical studies of largeand small-scale causal networks that are widespread in epidemiology, econometrics and climate science, are by contrast under way.

Mixedness does not make the science of well-being unique. Health and climate sciences are similar. Rather, the importance of this conclusion lies in the exciting new vistas it opens for philosophy of science. The existing categories of social versus natural science, interpretivism versus naturalism, ideographic versus nomothetic methods, will retain relevance only to the extent that they help us address real problems of these new disciplines. If they are of no discernible help, then it is best to ignore them for this case.

\section{A To-Do list for philosophers of science}

Now onto my agenda for a philosophy of the science of well-being. By necessity it is a partial agenda. As a mixed science, well-being research raises many of the same questions as other sciences: How to infer causality in the absence of experiment? How to test experimental findings and generalize from them? Can we trust first-person reports? And so on and so forth. Hence many items on the agenda of a philosophy of the science of well-being will overlap with agendas for the philosophy of biology, of sociology and of psychology, and general philosophy of science. I will concentrate here on two urgent items that have not received due attention:

1. Getting value-ladenness right.

2. Validating measures of well-being.

I will motivate them as crucial to any philosophy of the science of well-being, and present the notion of a mid-level theory that will enable progress on both.

\section{II.1. Getting Value-ladenness right}

Section I.1 argued that the science of well-being is value-laden in a specific fundamental way: its object of study is well-being, which has a normative component. But even if this is accepted as a legitimate feature of this project, as I have urged, there is still the question of how to practice such a science well. Value-ladenness of this sort raises difficult problems: can a science whose 
central category is normative still retain its objectivity? Can it avoid becoming merely a political tool? Can it retain the primacy of empirical evidence? In embracing value-ladenness the science of well-being commits to reckoning with these questions. In order to do so it needs, first, an account of value-aptness - let us use this term to mark a justifiable value-ladenness - and, second, a way of reconciling it with the standard demands we place on science.

Such an account does not currently exist. As already mentioned, of all the senses of value ladenness that philosophers of science have noted, ours is the closest to the case when preconceptions about, say, race and gender, enter into study design or the selection of evidence (Fox Keller and Longino 1996, Lloyd 2005). When a scientific study is designed around a thick concept such as well-being, the methodology of this study inherits this thickness. ${ }^{8}$ Take a standard claim in the science of well-being:

(F): Cause $\mathrm{C}$ impacts the well-being of a population $\mathrm{P}$ under circumstances I.

The adequacy of this claim needs to be judged both on normative and empirical grounds. It needs to be well supported by evidence and also value-apt. What would make F value-apt? We could start with a following obvious proposal:

(VA1): F is value-apt iff it employs an adequate conception of well-being.

Of course, VA1 alone is not very informative as everything rides on how we characterize this adequacy. For starters, measures of well-being are not always direct. Sometimes we measure by gauging determinants or correlates and VA1 needs to be sensitive to this fact. Secondly, if we demand that value-aptness requires employing a true account of well-being we quickly get into difficult issues at the core of metaethics about whether or not value claims have truth conditions. Holding the science of well-being hostage to metaethics is undesirable, so we should formulate value-aptness in a way that's neutral in the debates between cognitivists and expressivists, or between realists and antirealists. Even those who believe that moral, or in our case prudential, claims do not express facts (as non-cognitivists do) and that moral facts do not exist (as anti-realists do), should presumably wish to preserve the value-aptness of the science of well-being. It is this critical stance, that there are better and worse ways of conceptualizing well-being in science, that makes VA1 worth developing.

On the face of it, it is hard for VA1 to avoid taking a stance on the nature of wellbeing. The natural grounds for such a stance are the existing theories of wellbeing (also known as prudential value). Roughly, moral philosophers distinguish between three groups of theories of well-being: mental state theories, desire fulfillment theories, and objective list theories (see Tiberius 2006 for an overview and references). The best known version of mental state theories is hedonism; desire-based theories are known under the umbrella of subjectivism; and objective list theories subsume, among other theories, Aristotle's eudaimonism and its derivatives. Let us call these theories The Big Three. Although there is no agreement on which one is right, analytic ethics sports intricate and impressive versions within each approach. Depending on which of 
them one accepts as correct, (F) will come out value-apt or fail to do so. But perhaps it is too much to expect that scientists take a stand on the nature of wellbeing. How could a resolution of an ancient philosophical debate stand be a precondition for a scientific project?

One way to avoid it is to require that claims such as $\mathrm{F}$ are robust in the following way:

(VA2): $\mathrm{F}$ is value-apt iff the causal relationship it postulates stands on any conception of well-being.

The advantage of VA2 is that it promises to secure some neutrality without resorting to value-freedom. It invites us to make the claims of this science robust with respect to the values that underlie it. "Unemployment is bad for well-being" is only value-apt, on this view, if the unemployed fare badly on all of happiness, life satisfaction, and good functioning and hence come out as doing poorly on whichever of the Big Three we adopt. VA2 is an option worth exploring. At the very least, any causal claim about well-being that satisfies this constraint seems to be in better shape than ones that don't. But it also raises problems.

First of all, what is so sacred about The Big Three other than being the fruit of some two millennia of philosophy? Any substantive theory of well-being that does not fall into these camps (say, well-being consists in all and only knowledge of God) could be used in VA2 as well. But that would make it very hard indeed to maintain value-aptness for the science of well-being as currently practiced. None of the current measures try to detect the knowledge of God. In other words, we would need grounds to exclude certain theories of well-being.

Second, VA2 also damns as value-inapt any scientific finding that's not robust in the way it requires. Even restricting ourselves to the Big Three, we will encounter cases which one of the Big Three deems high on well-being while the others low. A miserable but fulfilled artist is a favorite example: she counts as well-faring on subjectivism but not on hedonism. One fascinating recent study offers evidence that income and economic indicators correlate much better with life satisfaction than with happiness (Kahneman and Deaton 2010). So depending on which measure of well-being we pick, pursuit of economic growth, rather than job protection, may or may not be a national priority. On VA2 such findings cannot be value-apt. Philosophers should weigh in on whether that may or may not be a price worth paying for value-aptness.

What then is a better conception of value-aptness? My own bet is with a relativized version of VA1:

(VA1'): $F$ is value-apt iff it employs an adequate conception of well-being given the context in which $\mathrm{F}$ is to be used.

I favor this option because it is unlikely that a single universal theory of wellbeing is forthcoming. But it is not too far-fetched to hope for theories of wellbeing with a specific though non-universal context of validity. I call these mid- 
level theories and will discuss them shortly. However, even this version comes with a danger: once a value-based decision is made about what measure of wellbeing to choose, it predetermines to some extent what we will find. Thus an Aristotelian objectivist who takes virtue to be essential to well-being will never discover well-faring knaves. Is that too close to wishful thinking? Does ideology dictate the science on VA1' in a way that compromises this science's objectivity? These are crucial and as yet unanswered questions.

\section{II.2 Validating measures of well-being.}

This brings us to the second agenda item. A measure of well-being is valid to the extent that it measures what it is supposed to. How do we determine validity? Although this issue is not unique to the science of well-being, it is worth putting it on the agenda because no other scientific project raises the stakes of this issue as much as this one. Depending on its resolution, strikingly different yardsticks will be adopted to judge the well-being of persons, communities and nations.

The nature of social measurement and validity are live foundational controversies (Cartwright and Bradburn 2010, Borsboom 2005, Angner 2013 among others). But everybody agrees that validating a measure of a phenomenon requires showing that this measure accords with our best theories of this phenomenon. Here I question that the most widely used approach to measure validation respects this requirement.

In the psychometric tradition, questionnaires are used to assign comparative values to the well-being of subjects to whom they are administered. These questionnaires must possess construct validity - the ability to detect the property in question. They range from gauging a person's feeling (How anxious do you feel?), to gauging their judgments (Is your life going according to your priorities?), or their perception of facts deemed important (Do you feel in control of your circumstances? Feeling generally healthy? Are you able to maintain personal hygiene? etc). They can be longer or shorter and administered through various media. What makes these questionnaires valid?

Roughly the process of validation is as follows: assemble all the questions you'd want to ask a person if you were interested in their well-being. Then reduce the number of these questions by eliminating the ones that seem to ask the same thing. Then have lots of people, as representative a sample as possible, answer these questions, possibly several times within various intervals. After that perform a battery of statistical tests on their answers. Which answers correlate? Which don't? Do they correlate over time when they should? Which questions best predict the overall score? And so on and so forth. Then select questions with the highest "factor loadings", test-retest reliability and other desirable psychometric properties. Compare how ratings of well-being based on these questionnaires correlate with other intuitively good ways of gauging well-being, say, a structured interview about how the person feels about their life. If the correlation is decent (anything above $r=.5$ is considered decent), then you have a valid measure of well-being. Of course, the actual procedures and tests can vary 
and become very sophisticated, but for our purposes this summary is a good enough approximation of the process of validation.

The methodological literature on how to design valid questionnaires in psychology and related sciences is enormous. And the store of questions that have passed these tests is enormous too, so much so that researchers are routinely discouraged from attempting to make their own questionnaires of anything at all. But little if any of this literature examines the fundamental assumptions of this approach. Why must a measure have good psychometric properties in order to be valid?

In conversation, practitioners routinely recognize that good psychometric properties are not sufficient for validity. It is accepted that the questionnaire items subjected to statistical analysis also have to be well grounded "theoretically", that is the questions must reflect our best theory of, in this case, well-being. But after this initial bit of theory, statistical analysis kicks in to determine which of the theoretically grounded questions are the right ones to ask. Of course, there are good reasons to filter questions in this way: for example, to make questionnaires shorter, standardized and comparable across time and place. But what if there is a conflict between psychometrics and theory? What if a seemingly bad measure has good psychometric properties? On the current setup, psychometrics wins just in virtue of being performed after the theory-based choice of questions.

I suspect that the motive behind this method is a view about who gets to judge well-being: unless the person filling out the questionnaire herself behaves as if the questions are about her well-being (as far as this can be detected by examining correlations between her answers), the questionnaire is not a valid measurement tool. Call this a sort of methodological subjectivism. Is it a good presupposition? Leah McClimans believes the method is not subjectivist enough. She notes its inability to ask "genuine questions", that is questions which allow subjects to contribute on their own terms, not just on the terms of the clinician posing the questions (McClimans 2010). McClimans would argue that a proper respect for subjects requires open interviews rather than prepackaged questionnaires. But we can also question the assumption that people themselves are reliable judges of what their well-being is. As a substantive empirical claim it is being challenged left and right in philosophy and cognitive science (Haybron 2007, Schwitzgebel 2008, Wilson 2009). Perhaps methodological subjectivism is not an empirical claim about people's actual competence to judge, but a moral claim about the respect that we owe to their judgments? Or even a pragmatic claim about there being no other source of evidence about how they are doing?

How to balance theoretical considerations about the nature of human well-being with pragmatic demands of ease of use, precision, and comparability, is an open question of enormous philosophical and practical importance that is only beginning to be tackled by philosophers. In my view any theory of measure validation will need to rely on mid-level theories of well-being, to which I turn now. 


\section{II.3 Towards Mid-level Theories of Well-being.}

Making progress on the problems of value-aptness and measure validation will take a lot more than I can offer in the remainder of this article. But I do have one proposal to offer: both problems call for a new way of theorizing.

In the science of well-being the object of theorizing is well-being. We might be tempted by the following simple division of labor: philosophers (or scientists in their philosophical moments) do the foundational normative work by telling us what well-being is, while scientists (or philosophers in their empirical moments) investigate the network of causes and correlates of the particular state identified by the first inquiry. Call the two kinds of theories constitutive and causal. A causal theory of well-being specifies the network of mechanisms that brings about well-being. A constitutive theory tells us what to measure for this object or property to count as well-being in the first place. If we believe the disciplinary consensus in ethics, we do not need any more constitutive theories, for we already have more than enough, that is the Big Three. So now the ball is in the scientists' court to produce causal theories.

There are many reasons to reject this division of labor. Valerie Tiberius argues that the thickness of well-being as a concept makes it proper that some empirical facts about what people value and how they act when they are faring well become part and parcel of what well-being is (Tiberius 2013). Michael Bishop (2012) proposes that well-being be identified with the causal network that it typically instantiates, thus also blurring the boundary between the causal and constitutive.

Similarly, if we take the idea of a mid-level theory seriously, the distinction becomes less important. If high theories are about persons in the broadest possible sense without any context, mid-level theories are theories of well-being about kinds of people in kinds of circumstances: children, children in the welfare system, former child-soldiers, working mothers, caretakers of the ill, Britain, etc. They are mid-level because they are in between the high-church Big Three, and very specific measures of well-being in practical contexts. By necessity then, these theories are about the conditions of actual flourishing of these kinds given their environments. So these theories would likely be both causal and constitutive, both empirical and normative. To some degree it does not matter to a mid-level theorist where we draw the line between what well-being really is and what is its cause or background condition.

Where do mid-level theories come from? Implicitly they already exist. Elsewhere I have observed that the science of well-being exhibits construct pluralism, that is in different contexts of research scientists focus on different properties as essential to well-being. Thus depending on whether scientists study children, or countries, or depressed mothers, or frail widowers they adopt a different definition of well-being, not just a different measure. In medical contexts wellbeing is more health-based, in psychiatry - flourishing-based, in some 
sociological contexts it is based on control over one's life, in education - on the development of important capacities, and so on and so forth (Alexandrova 2012).

It is an implicit mid-level theory that motivates specialists on child well-being to attend to play and attachment, while specialists on national well-being focus on the sustainable use of resources, to use two vivid examples. But these theories are not well-worked out and not well connected to measurement, policy goals and the Big Three. In my view, these latter tasks are urgent and also the perfect use of the skills of philosophers of science and ethicists.

Once we attempt to formulate mid-level theories explicitly we see the limits and advantages of high theories. The main limitation is that hedonism, subjectivism or eudaimonism alone are not sufficiently detailed to yield an account of wellbeing of, say, children. ${ }^{9}$ Do all childhood pleasures matter? Which, if any, of the child's desires matter? Which virtues should a child exercise to fare well? Answers to these questions require going beyond the resources of the high theories. They require attending to the nature of children and their development. The high theorist might object that these are just facts necessary for the careful application and no mid-level theory is called for. I disagree. Developmental psychologists, social workers, doctors, teachers have a great deal of fairly systematic normative knowledge about the nature of children and their development.

In addition to this, high theories disagree on the nature of well-being. These disagreements are so fundamental that, if taken seriously, would paralyze the science of well-being. No recourse can be sought in facts that these theories might agree on, for these facts are mere platitudes (such as "pleasure matters"). These platitudes are not sufficiently detailed for scientific purposes. But the Big Three are far from useless. They provide the conceptual tools - balance of pleasures and pains, rational preferences, flourishing. Mid-level theories can and do use these tools to build up accounts of well-being of children, chronically ill, the depressed, nations, etc. High theories of well-being do not come with a full rulebook on how to use them for all the tasks at hand, but they are essential and valuable nonetheless just as high theories in physics are.

I believe that mid-level theories of well-being are necessary (though perhaps not sufficient) for securing value-aptness and the validity of measures. But apart from this mid-level theorizing also presents a case study for philosophers of science who have long been interested in the relations between theory on the abstract end of the spectrum, observation on the concrete end, and models in between. No sharp distinctions between the three can be drawn, but these categories are nevertheless enormously useful for understanding the structure of physical, biological and some social sciences. Here too the difficult task of applying our knowledge of well-being is illuminating as a philosophical, scientific and a policy problem. 


\section{Works Cited:}

Alexandrova, Anna. "Well-being as an Object of Science" Philosophy of Science 79 (5) (2012):678-689.

Anderson, Elizabeth. "Uses of value judgments in science: A general argument, with lessons from a case study of feminist research on divorce." Hypatia 19 (1) (2004):1-24.

Angner, Erik. "Subjective measures of well-being: Philosophical perspectives". In Harold Kincaid \& Don Ross (eds.), The Oxford Handbook of Philosophy of Economics. Oxford University Press. (2009)560-579.

Angner, Erik. Is it possible to measure happiness? European Journal for Philosophy of Science 3 (2) (2013):221-240.

Benjamin, Daniel J., et al. "Beyond Happiness and Satisfaction: Toward WellBeing Indices Based on Stated Preference." American Economic Review 104(9), (2014) 2698-2735.

Bishop, Michael. "The Network Theory of Well-Being: An Introduction." The Baltic International Yearbook of Cognition, Logic and Communication [Online], 7 (2012): 1-29. Accessed 1 Aug. 2013

Borsboom, Denny. Measuring the mind: Conceptual issues in contemporary psychometrics. Cambridge University Press, 2005.

Camfield, Laura, Gina Crivello, and Martin Woodhead. "Well-being research in developing countries: Reviewing the role of qualitative methods." Social Indicators Research 90.1 (2009): 5-31.

Cartwright, Nancy D and Bradburn, N. 'A Theory of Measurement', The Importance of Common Metrics for Advancing Social Science Theory and Research: Proceedings of the National Research Council Committee on Common Metrics. April 2011, pp. 53-70.

Chase-Lansdale, P. Lindsay, Robert A. Moffitt, Brenda J. Lohman, Andrew J. Cherlin, Rebekah Levine Coley, Laura D. Pittman, Jennifer Roff, and Elizabeth Votruba-Drzal. "Mothers' transitions from welfare to work and the well-being of preschoolers and adolescents." Science 299, no. 5612 (2003): 1548-1552.

Dasgupta, Partha. Human Well-Being and the Natural Environment. Oxford: Oxford University Press. 2001.

Diener, Edward., R. Lucas, U. Schimmack and J. Helliwell. Well-being for Public Policy. New York: Oxford University Press. 2008.

Diener, Edward. "New findings and future directions for subjective well-being research". American Psychologist, 67(8), 590. (2012). 
Diener, Edward, and Eunkook M. Suh, eds. Culture and subjective well-being. MIT press. (2000)

Douglas, Heather. Science, Policy and the Value Free Ideal, Pittsburgh University Press. 2009.

Einarsdóttir, Jónína. "Happiness in the neonatal intensive care unit: Merits of ethnographic fieldwork." International journal of qualitative studies on health and well-being (2012)7:1-9.

Evelyn Fox Keller \& Helen E. Longino (eds.) (1996). Feminism and Science. Oxford University Press.

Guala, Francesco. "The Philosophy of Social Science: Metaphysical and Empirical”. Philosophy Compass 2 (6) (2007):954-980.

Hacking, Ian. Rewriting the Soul: Multiple Personality and the Sciences of Memory. (1995) Princeton University Press.

Haybron, Daniel M. "Do we know how happy we are? On some limits of affective introspection and recall." Nous 41.3 (2007): 394-428.

Kahneman, Daniel, and Angus Deaton. "High income improves evaluation of life but not emotional well-being." Proceedings of the National Academy of Sciences 107.38 (2010): 16489-16493.

Kahneman, Daniel, and Alan B. Krueger. "Developments in the measurement of subjective well-being." The journal of economic perspectives 20.1 (2006): 3-24.

Kahneman, D, A. Krueger, D. Schkade, N. Schwartz \& A. Stone.. "Toward National Well-Being Accounts". American Economic Review (May) (2004a) 429-434.

Kahneman, Daniel, Alan B. Krueger, David A. Schkade, Norbert Schwarz, and Arthur A. Stone. "A survey method for characterizing daily life experience: The day reconstruction method." Science 306, no. 5702 (2004b): 1776-1780.

Kincaid, Harold, John Dupre and Alison Wylie (eds) Value-Free Science? Ideals and Illusions, (2007). New York: Oxford University Press.

Kirchin, Simon, ed. Thick Concepts. OUP Oxford, 2013.

Kopinak, Janice Katherine. "The use of triangulation in a study of refugee wellbeing." Quality and Quantity 33, no. 2 (1999): 169-183.

Kuhn, Thomas S. The Structure of Scientific Revolutions. University of Chicago Press, (1962).

Layard, Richard. Happiness: Lessons from a new science. (2005) London: Penguin. 
Little, Daniel. Varieties of Social Explanation: An Introduction to the Philosophy of Social Science, (1991) Westview Press, Boulder, CO.

Lacey, Hugh. Is Science Value Free?: Values and Scientific Understanding. (1999) Routledge.

Lloyd, Elisabeth Anne. The case of the female orgasm: Bias in the science of evolution. 2005 Harvard University Press.

Loewenstein, George. (2009). That which makes life worthwhile. In Alan B.Krueger (ed.) Measuring the Subjective Well-Being of Nations: National Accounts of Time Use and Well-Being (pp. 87-106). University of Chicago Press.

Lucas, Richard E. "Adaptation and the Set-Point Model of Subjective Well-Being Does Happiness Change After Major Life Events?." Current Directions in Psychological Science 16.2 (2007): 75-79.

Lucas, Richard E. "Does life seem better on a sunny day? Examining the association between daily weather conditions and life satisfaction judgments." Journal of Personality and Social Psychology, (2013), 104, 872-884.

McClimans, Leah. "A theoretical framework for patient-reported outcome measures." Theoretical Medicine and Bioethics 31 (3) (2010):225-240.

Nagel, Ernest. The Structure of Science: Problems in the Logic of Scientific Explanation. (1961) New York: Harcourt, Brace \& World, Inc.

Nussbaum Martha and Amartya Sen (eds) The Quality of Life. (1993) Oxford: Clarendon Press.

Dorsett, Richard and Oswald, Andrew J. (2014) Human well-being and in-work benefits : a randomized controlled trial. Working Paper. Coventry, UK:

Department of Economics, University of Warwick. Warwick economics research papers series (TWERPS), Volume 2014 (Number 1038).

Raghavan, Ramesh, and Anna Alexandrova. "Toward a Theory of Child WellBeing." Social Indicators Research (2014): 1-16.

Steel, Daniel. "Naturalism and the Enlightenment ideal : rethinking a central debate in the philosophy of social science". In P. D. Magnus \& Jacob Busch (eds.), New Waves in Philosophy of Science. Palgrave Macmillan, (2010).

Steel, Daniel \& Guala, Francesco (eds.) The Philosophy of Social Science Reader. (2010) Routledge.

Stiglitz, Joseph E., Amartya Sen, and Jean-Paul Fitoussi. "Report by the commission on the measurement of economic performance and social progress." 
Paris: Commission on the Measurement of Economic Performance and Social Progress (2010).

Schwitzgebel, Eric. "The unreliability of naive introspection." Philosophical Review 117.2 (2008): 245-273.

Taylor, Charles. "Interpretation and the sciences of man." The review of metaphysics, 25/1(1971): 3-51.

Tiberius, Valerie. "Well-Being: Psychological Research for Philosophers". Philosophy Compass, 1(2006): 493-505. doi: 10.1111/j.1747-9991.2006.00038.x

Tiberius, Valerie (2013). "Thick Theorizing: on the Division of Labor between Moral Philosophy and Positive Psychology". In Kirchin (2013) 217-234.

Wilson, Timothy D. Strangers to ourselves: Discovering the adaptive unconscious. Harvard University Press, 2009.

\footnotetext{
${ }^{1}$ I dedicate this article to the anonymous referee who helped me with it. Your devotion, patience and charity taught me both moral and philosophical lessons. When I referee in the future I will try to live up to the ideal that you have so well instantiated. Thank you. ${ }^{2}$ Little 1991 is a typical textbook. Taylor 1971 is a classic of $20^{\text {th }}$ century exceptionalism from a tradition going back to German Idealism.

${ }^{3}$ Contemporary philosophy of social science is moving away from the naturalism vs interpretivism debate focusing instead on the specific methodological problems in social research that on reflection are hardly unique to social sciences. (Guala 2007, Steel and Guala 2010)

${ }^{4}$ See Taylor 1971 for a famous critique and Nagel 1961 for a defense.

5 See Kincaid et al 2007, Lacey 1999 and especially Douglas 2009 for the latest on the various roles of values in science.

${ }^{6}$ Nagel did not use this example, nor did he use the expression "thick concepts" later popularized by Bernard Williams. Thick concepts (shame, guilt, wisdom), unlike thin ones (good, right), are known for the entanglement of normative and descriptive content. For more on their role in the science of well-being see Tiberius 2013. The notion of thick concepts is now fairly mainstream in philosophy, but their characterization is far from uncontroversial (Kirchin 2013).

${ }^{7}$ For examples see the work by Martin Seligman and Felicia Huppert, among others.

${ }^{8}$ See Anderson 2004 on divorce and Hacking 1995 on trauma for other examples. Valueladenness derived from thickness of concepts is neither specific to the science of wellbeing, nor is it specific to social science. (So those who are hopeful of reviving a philosophy of social science in general should not pin their hopes on value-aptness as a defining feature of social science.) Medical and biological sciences that operate with concepts of health, biodiversity and the like, need to care about value-aptness just as much.

${ }^{9}$ See Raghavan and Alexandrova 2014 on how to construct a theory of child well-being.
} 